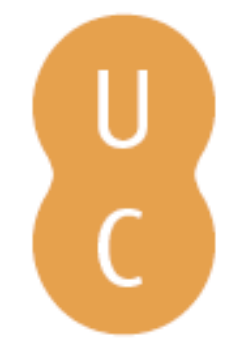

\title{
pommalina
}

\section{Avaliação do risco no município de Benguela, Angola}

Autor(es): $\quad$ Estevão, Wladimir Borges; Tavares, Alexandre Oliveira

Publicado por: Imprensa da Universidade de Coimbra; RISCOS - Associação

Portuguesa de Riscos, Prevenção e Segurança

URL

persistente: URI:http://hdl.handle.net/10316.2/34938

DOI: $\quad$ DOI:http://dx.doi.org/10.14195/978-989-96253-3-4_138

Accessed : $\quad$ 26-Apr-2023 12:12:07

A navegação consulta e descarregamento dos títulos inseridos nas Bibliotecas Digitais UC Digitalis, UC Pombalina e UC Impactum, pressupõem a aceitação plena e sem reservas dos Termos e Condições de Uso destas Bibliotecas Digitais, disponíveis em https://digitalis.uc.pt/pt-pt/termos.

Conforme exposto nos referidos Termos e Condições de Uso, o descarregamento de títulos de acesso restrito requer uma licença válida de autorização devendo o utilizador aceder ao(s) documento(s) a partir de um endereço de IP da instituição detentora da supramencionada licença.

Ao utilizador é apenas permitido o descarregamento para uso pessoal, pelo que o emprego do(s) título(s) descarregado(s) para outro fim, designadamente comercial, carece de autorização do respetivo autor ou editor da obra.

Na medida em que todas as obras da UC Digitalis se encontram protegidas pelo Código do Direito de Autor e Direitos Conexos e demais legislação aplicável, toda a cópia, parcial ou total, deste documento, nos casos em que é legalmente admitida, deverá conter ou fazer-se acompanhar por este aviso.

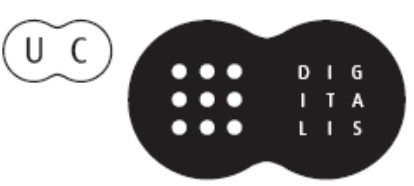



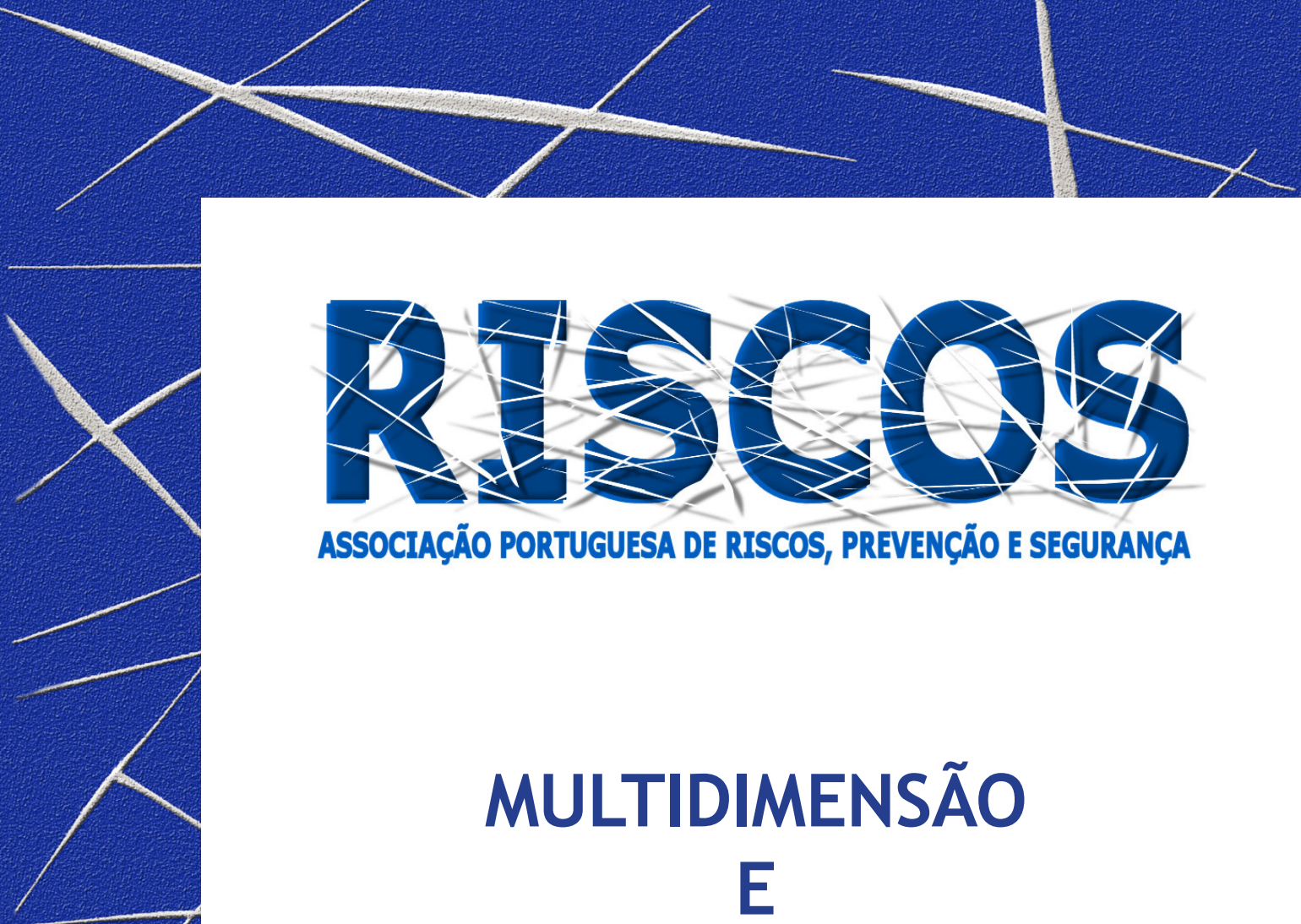

ASSOCIAÇÃO PORTUGUESA DE RISCOS, PREVENCCÃO E SEGURANÇA

MULTIDIMENSÃO

E
TERRITÓRIOS DE RISCO

III Congresso Internacional

I Simpósio Ibero-Americano

VIII Encontro Nacional de Riscos

Guimarães

2014 


\title{
AVALIAÇÃO DO RISCO NO MUNICÍPIO DE BENGUELA, ANGOLA
}

\author{
Wladimir Borges Estevão \\ Ministério da Educação, Benguela, Angola \\ wladimirestevao2012@hotmail.com \\ Alexandre Oliveira Tavares \\ Centro de Estudos Sociais e Dep. Ciências da Terra da Universidade de Coimbra \\ atavares@ci.uc.pt
}

\begin{abstract}
RESUMO
Os riscos materializam processos ou acções, naturais ou tecnológicos, que adquirem relevância socioeconómica e que têm expressão territorial, os quais condicionam as políticas públicas e a qualidade de vida dos cidadãos. Com este trabalho identificam-se os processos perigosos, de origem natural e tecnológica que afectam a população do município de Benguela, Angola. Faz-se de seguida uma avaliação do grau de risco para os principais processos, utilizando a probabilidade e gravidade dos impactos associados. Foram identificados 13 processos principais de perigo, de origem natural e tecnológica, com impacto e danos materiais e humanos no município de Benguela. Na análise do grau de risco recorreu-se à matriz harmonizada utilizada pela ANPC e à matriz das três variáveis (Standards Australia, 2004). Como base na classificação do grau de risco evidenciaram-se os galgamentos costeiros, a seca e abaixamento dos níveis de águas, os acidentes ou incêndios com material eléctrico, em resíduos ou edifícios habitacionais e os acidentes rodoviários. Apresentam ainda graus elevados as cheias e inundações, as tempestades e trovoadas com chuvas intensas, a par da instabilidade de taludes e arribas.
\end{abstract}

Palavras-chave: Riscos naturais, riscos tecnológicos, grau de risco, Benguela, Angola.

\section{Introdução}

Os riscos materializam processos ou acções, naturais ou tecnológicos, que adquirem relevância sócio-económica e têm expressão territorial, constituindo a análise e gestão dos riscos fora de acção e decisão integrantes das actividades em sociedade (Cantos e Ayala-Carcedo, 2002). Nas sociedades atuais verifica-se um aumento da consciência individual e coletiva quanto aos potenciais perigos, por parte dos cidadãos, técnicos, cientistas e agentes políticos, os quais se organizam cada vez mais em torno desta problemática (Tavares et al., 2014). Estes intervenientes procuram através do ordenamento e planeamento, bem como nas instituições da proteção civil, melhorar a capacidade de gestão dos riscos.

Em Angola o crescimento das grandes cidades, em particular após a independência, devido a factores de atração e segurança, a par do êxodo rural, coloca novos problemas na gestão do espaço urbano, assim como na segurança das comunidades e cidadãos. Os impactos dos processos naturais e tecnológicos têm vindo a adquirir maior importância social e institucional, em resultado das consequências e da recorrência dos acidentes e desastres, em que o município de Benguela é um exemplo.

\section{Área de Estudo}

A área de estudo, o Município de Benguela, localiza-se na província de Benguela, em Angola, a qual se situa na zona litoral centro. O município ocupa uma área de $2.100 \mathrm{~km}^{2}$ (Figura 1). A população está estimada em 887.756 habitantes, com uma densidade populacional de 355,7 $\mathrm{hab} / \mathrm{km}^{2}$ (PDMB, (2012). 


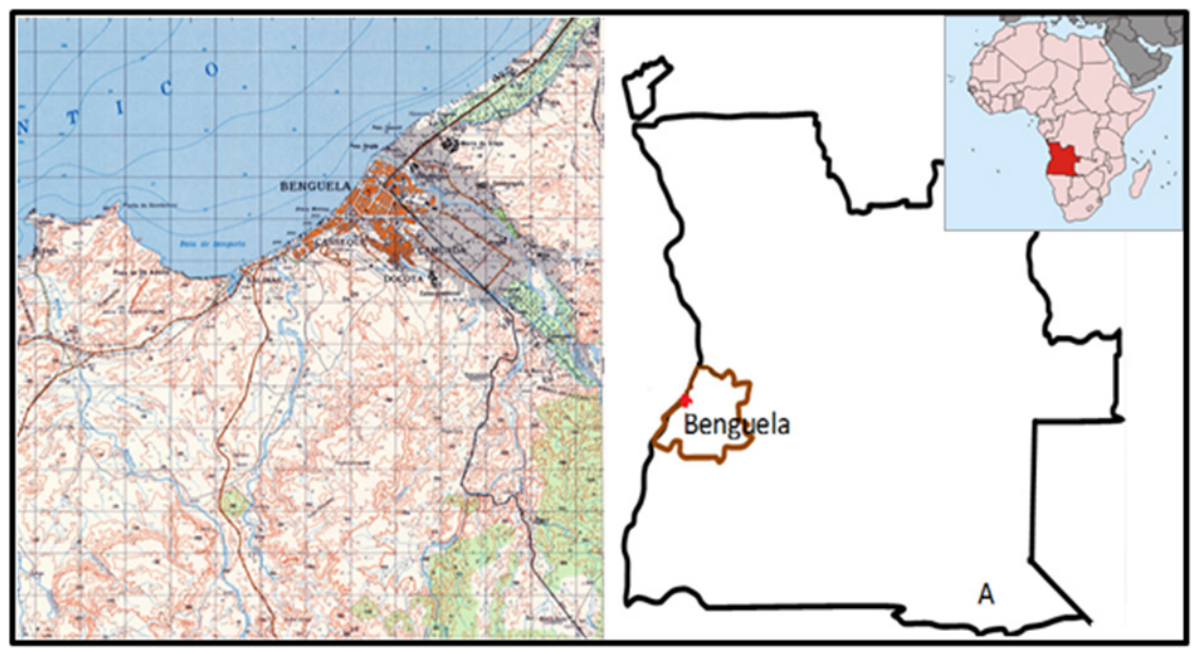

Figura 1 - Localização da área de estudo

O Município dispõe de Serviços de Proteção Civil e Bombeiros, o qual conta com sete viaturas operacionais de combate a incêndios, quatro lanchas, duas motas aquáticas e um barco, assim como os serviços de emergência médica do INEMA. Os Serviços de Proteção Civil estão dotados de um Sistema de Aviso Prévio (SAP) para controle e alerta de riscos de inundação, e contam ainda com o serviço Praias Seguras de Angola (PSA), que é executado por mergulhadores e nadadores-salvadores

\section{Metodologia}

A avaliação dos principais perigos e impactos associados baseou-se em recolhas de campo sobre registos históricos de ocorrências de acidentes naturais e tecnológicos em várias áreas do município, assim como nas reconstituições e perceções dos diferentes agentes da proteção civil ou de responsáveis, directos ou indirectos, pela gestão ou comunicação do risco, para os quais foram aplicados questionários abertos.

Após a análise foi avaliada a gravidade e a probabilidade de ocorrência para cada um dos processos perigosos presentes, naturais e tecnológicos. Utilizaram-se matrizes de análise de risco que permitem graduar o nível do risco a partir das suas componentes fundamentais: a previsibilidade do evento de risco se vir a concretizar e as suas potenciais consequências Coelho (2007). Para esta análise utilizou-se a metodologia apontada pela Autoridade Nacional de Proteção Civil de Portugal no caderno técnico PROCIV9 (ANPC, 2009). Para complementar a avaliação utilizou-se a metodologia das Três Variáveis HB205-2004 (Standards Australia, 2004), que inclui como parâmetros de análise as Consequências (C), a Exposição (E) e a Probabilidade (L).

\section{Avaliação e Análise do Risco}

A base de dados elaborada para os processos perigosos no município de Benguela, fez ressaltar os elevados danos e perdas pessoais e materiais associados às cheias e inundações, tempestades e trovoadas com chuvas intensas, incêndios em habitações e outros edifícios e acidentes de viação. 
Foi ainda revelada a importância dos danos materiais associados aos galgamentos costeiros e secas. As cheias e inundação são sistematicamente referenciadas pelos elevados impactos sociais, com o aparecimento de elevado número de desalojados e perdas materiais em habitações e na agricultura, mas também com vítimas mortais e feridos. As perdas humanas foram particularmente relacionadas com as quedas de barreiras, taludes ou muros, com acidentes ferroviários, ou com acidentes com material eléctrico. A sinistralidade rodoviária emerge como o principal riscos do município dada a frequência e os elevados impactos, com feridos, vítimas mortais e danos materiais.

As margens do rio do Cavaco, o Bairro do Calomburaco, o Bairro do Cotel, o Bairro da Calomanga e o Bairro da Seta, assim como a vala de Coringe, a Praia Morena e a Caota, são as áreas mais expostas aos riscos naturais e tecnológicos no município.

$\mathrm{Na}$ Tabela I aparecem identificados os graus de risco para cada um dos principais processos naturais para o município de Benguela, segundo a matriz da ANPC (2009). É de realçar o grau elevado ou extremo para cinco dos seis processos analisados, apresentando os graus mais elevado as secas, com as consequências associadas ao abaixamento dos níveis de água nos rios, valas e poços, assim como os galgamentos costeiros. Salienta-se como moderados os processos de erosão ravinante presentes em algumas arribas e vertentes, como as localizadas na zona do S. António.

Tabela I - Grau de risco para os processos naturais pela matriz ANPC (ANPC, 2009).

\begin{tabular}{|c|c|c|c|}
\hline Processo & Gravidade & Probabilidade & Grau de risco \\
\hline Cheias e inundações & Acentuada & Média-alta & Risco Elevado \\
\hline Tempestades e trovoadas com chuva intensa & Acentuada & Média-alta & Risco Elevado \\
\hline Secas e abaixamento dos níveis de água & Acentuada & Elevada & Risco Extremo \\
\hline Galgamentos costeiros & Acentuada & Elevada & Risco Extremo \\
\hline Instabilidade de taludes e arribas & Acentuada & Média-alta & Risco Elevado \\
\hline Erosão de ravinas & Reduzida & Elevada & Risco Moderado \\
\hline
\end{tabular}

$\mathrm{Na}$ Tabela II surgem os resultados para os processos ou acidentes tecnológicos analisados com a matriz da ANPC (2009). Salientam-se os graus extremos para os acidentes rodoviários, assim como os relacionados com os acidentes ou incêndios com material eléctrico, originados por curto-circuitos, por manuseamento indevido aquando de ligações a fontes de distribuição eléctrica, por electrocução associada à queda de cabos e postes eléctricos ou por contacto com fontes ou cabos/fios de corrente eléctrica. Os incêndios em habitações ou em depósitos de resíduos mal acondicionados/lixos, resultam do fogo para cozinhar e iluminar, ou decorrente de curto-circuitos ou sobrecarga dos sistemas ou do uso indevido.

Tabela II - Grau de risco para os processos ou acidentes tecnológicos pela matriz ANPC

\begin{tabular}{|c|c|c|c|}
\hline Processo & Gravidade & Probabilidade & Grau de risco \\
\hline Acidentes rodoviários & Crítica & Elevada & Risco Extremo \\
\hline Acidentes ou incêndios com material eléctrico & Acentuada & Elevada & Risco Extremo \\
\hline Incêndios de resíduos ou edifícios habitacionais & Acentuada & Elevada & Risco Extremo \\
\hline Contaminação de solos e cursos de água & Moderada & Elevada & Risco Elevado \\
\hline Contaminação marítima & Moderada & Média-alta & Risco Elevado \\
\hline Contaminação atmosférica & Reduzida & Elevada & Risco Moderado \\
\hline
\end{tabular}


A análise do risco segundo a matriz das três variáveis (Standards Australia, 2004) aparece representada na Tabela III.

Tabela III - Grau de risco segundo a matriz das três variáveis.

\begin{tabular}{|c|c|c|c|c|c|}
\hline Processo & Consequências C & Exposição E & Probabilidade L & Score & Grau de Risco \\
\hline Cheias e inundações & 50 & 2 & 3 & 300 & Elevado \\
\hline Tempestades com chuvas intensas & 50 & 2 & 3 & 300 & Elevado \\
\hline Secas e abaixamento dos níveis de água & 25 & 2 & 6 & 300 & Elevado \\
\hline Galgamentos costeiros & 50 & 2 & 6 & 600 & M. Elevado \\
\hline Instabilidade de taludes e arribas & 50 & 1 & 2 & 100 & Moderado \\
\hline Erosão de ravinas & 5 & 2 & 6 & 60 & Baixo \\
\hline Acidentes rodoviários & 50 & 10 & 10 & 3000 & M. Elevado \\
\hline Acid. ou incêndios com mat. eléctrico & 50 & 2 & 3 & 300 & Elevado \\
\hline Incêndios em resíduos ou ed. habitac. & 50 & 2 & 3 & 300 & Elevado \\
\hline Contaminação de solos e de águas & 15 & 3 & 6 & 270 & Moderado \\
\hline Contaminação marítima & 15 & 2 & 3 & 90 & Moderado \\
\hline Contaminaçáo atmosférica & 1 & 6 & 10 & 60 & Baixo \\
\hline
\end{tabular}

Sobressaem pelo grau muito elevado os galgamentos costeiros e os acidentes rodoviários. Com grau elevado de risco aparecem as cheias e inundações, tempestades e trovoadas com chuvas intensas, acidentes ou incêndios com material eléctrico e os incêndios em resíduos ou edifícios. Os problemas de contaminação e a instabilidade de taludes, arribas e quedas de muros apresentam grau de risco moderado, em função do baixo valor ou das consequências, ou da exposição ou da probabilidade. 0 valor mais baixo de grau de risco está associado à erosão ravinantes de arribas e vertentes.

\section{Conclusões}

Em síntese, o município de Benguela apresenta elevados a muito elevados graus de risco em processos, quer naturais, quer tecnológicos. As duas metodologias de avaliação do grau de risco fizeram salientar pelas classes muito elevadas ou extremas os galgamentos costeiros ou calemas e os acidentes rodoviários. As duas metodologias salientam os graus moderados ou baixos para os processos de erosão ravinante e para a contaminação atmosférica por poeiras. Genericamente pode-se dizer que a matriz utilizada pela ANPC origina valores mais elevados de grau de risco, quando se compara com os resultados da matriz das três variáveis.

Os únicos processos que apresentam graus de risco afastados nas duas matrizes, são a instabilidade de taludes e arribas, a contaminação de solos e águas, e a contaminação marítima. De acordo com os elevados ou muito elevados graus de risco encontrados para o município de Benguela, faz sentido desenvolver acções de prevenção, redução e mitigação do risco, para aumentar o grau de segurança das populações.

\section{Referências Bibliográficas}

ANPC (2009). Cadernos Técnicos PROCIV 9. Guia Para Caracterização de Risco no Âmbito da Elaboração de Planos de Emergência de Protecção Civil. Autoridade Nacional de Protecção Civil, Lisboa 28p.

Cantos, J. \& Ayala-Carcedo, F. (2002). Riesgos Naturals, Conceptos Fundamentals y Clasificación. In AyalaCarcedo, Francisco \& Cantos, Jorge (Ed.) - Riesgos Naturales, Arial Ciencia, Barcelona, pp. 41-73.

Coelho, J.M. (2007). A Matriz Harmonizada de Risco ' 'O Canivete Suíço ' dum sistema integrado de Gestão do Risco Industrial). Riscos Públicos e Industriais vol. 1, Edições Salamandra, Lisboa.

PDMB, (2012). Plano Director Municipal de Benguela. Regulamento. Proposta do Plano. Governo Provincial de Benguela Direcção Provincial do Ordenamento do Território, Urbanismo e Ambiente. Documento Reservado. 
Standards Australia. (2004). HB205-2004 OHS Risk Management Handbook. Sydney, Standards Australia.

Tavares, Alexandre Oliveira; Santos, Pedro (2014). Re-scaling risk governance using local appraisal and community involvement. Journal of Risk Research, 17, 7, 923-949. 